\title{
Relationships between insulin release and taste
}

\author{
Kazuyuki TonOSAKI ${ }^{1}$, Yasunori HoRI ${ }^{1}$, Yasutake SHIMIZu ${ }^{2}$ and Keiichi TonosAKI ${ }^{1}$ \\ ${ }^{1}$ Department of Oral Physiology, School of Dentistry, Meikai University, Saitama 350-0283 and ${ }^{2}$ Department of Veterinary Physiology, \\ Faculty of Agriculture, Gifu University, Gifu, Japan
}

(Received 13 December 2006; and accepted 26 January 2007)

\begin{abstract}
Tasting sweet food elicits insulin release prior to increasing plasma glucose levels, known as cephalic phase insulin release (CPIR). The characteristic of CPIR is that plasma insulin secretion occurs before the rise of the plasma glucose level. In this experiment, we examined whether taste stimuli placed on the tongue could induce CPIR. We used female Wistar rats and five basic taste stimuli: sucrose (sweet), sodium chloride (salty), $\mathrm{HCl}$ (sour), quinine (bitter) or monosodium glutamate (umami). Rats reliably exhibited CPIR to sucrose. Sodium chloride, $\mathrm{HCl}$, quinine, or monosodium glutamate did not elicit CPIR. The non-nutritive sweetener saccharine elicited CPIR. However, starch, which is nutritive but non-sweet, did not elicit CPIR although rats showed a strong preference for starch which is a source of glucose. In addition, we studied whether CPIR was related to taste receptor cell activity. We carried out the experiment in rats with bilaterally cut chorda tympani nerves, one of the gustatory nerves. After sectioning, CPIR was not observed for sweet stimulation. From these results, we conclude that sweetness information conducted by this taste nerve provides essential information for eliciting CPIR.
\end{abstract}

Taste sensations have been classified into five submodalities: sweet, salty, sour, bitter, and umami, which typically represent particular categories of stimuli. Sweetness is represented by carbohydrates, sourness by spoilage materials, salt by minerals, bitterness by toxic substances, and the umami by amino acids. On the basis of these signals, animals discriminate between nutrient and toxic substances. The sense of taste involves not only responding to foods and transmitting the chemical information of the food to the central nervous system but also setting up appropriate caloric intake action and taste related reflexes $(3,4)$. For example, strong sourness increases secretional saliva $(4,6,9)$ which helps to

Address correspondence to: Dr. Keiichi Tonosaki Department of Oral Physiology, School of Dentistry, Meikai University, 1-1 Keyakidai, Sakatoshi, Saitamaken, Japan 350-0283

Tel (Fax): +81-49-279-2770

E-mail: tonosaki@dent.meikai.ac.jp prepare for smooth digestion and absorption of food before it reaches the stomach. It is also known that taste stimuli can produce insulin secretion via the $\beta$ cell of the pancreas $(1-3,6)$. The characteristic of cephalic phase insulin release (CPIR) is that plasma insulin secretion occurs before the rise of the plasma glucose level. The typical characteristic of CPIR is that plasma insulin is secreted within 2 min after oral sensory stimulation, peaks at $4 \mathrm{~min}$, and returns to baseline within $8-10$ min after stimulation $(4,6$, 14-18). Although many CPIR related experiments have been conducted using multiple animal species, including human, the functional role of CPIR is not clearly known (1, 3, 6-10). In CPIR research, food substances are typically placed in the oral cavity. In many cases, more attention is paid to "food composition" than to "food taste" $(6,7,13)$. There is no report that examines the effect of the 5 submodalities of taste on CPIR systematically. It is important to clarify this relationship between qualities of tastes and CPIR. The purpose of this study is to clarify the 
characteristics of taste specificity of CPIR using the rat.

\section{MATERIALS AND METHODS}

Animals. Male Wistar rats weighting 120-220 g were housed in plastic cages at $22 \pm 1{ }^{\circ} \mathrm{C}$ with a $12: 12 \mathrm{~h}$ light: dark cycle (light on $07: 00-19: 00 \mathrm{~h}$ ). They were given free access to laboratory chow (LABO MR Sttock, Nihon-Nosan, Yokohama, Japan) and water.

Taste solutions. Taste stimuli were sucrose $(1.0 \mathrm{M}$, sweetness), acetic acid $\left(\mathrm{CH}_{3} \mathrm{COOH}, 0.1 \mathrm{M}\right.$, sourness), salt ( $\mathrm{NaCl}, 0.5 \mathrm{M}$, salty taste), quinine hydrochloride ( $\mathrm{QHCl}, 0.01 \mathrm{M}$, bitterness), sodium glutamate (MSG, $0.2 \mathrm{M}$, umami), saccharin $(0.01 \mathrm{M})$, and starch (5\%, Merck KgaA, Germany). Each chemical was dissolved in distilled water.

Neural recording procedure. After the rat was sufficiently anesthetized with pentobarbital administration $(40 \mathrm{mg} / \mathrm{kg}$, i.p.), the trachea was cannulated. The rat was fixed in a supine position in a head folder, and the chorda tympani (CT) nerve was exposed and cut near its entry into the tympanic bulla. For whole nerve recording, the entire nerve was placed on a bipolar silver wire electrode. The electrophysiological recording method as well as the methods for chemical stimulation of the taste cells have been previously described (12). Each chemical solution was applied to the tongue for $20 \mathrm{~s}$. Solutions were delivered at a flow rate of $0.5 \mathrm{~mL} / \mathrm{s}$. Interstimulus intervals were at least $1 \mathrm{~min}$, during which time the tongue was rinsed with distilled water.

Behavioral analysis (two bottle preference tests). Rats were first trained to drink at equal rates from two bottles of distilled water. After training, distilled water was kept in one bottle while a test solution was placed in the other. The position of the bottle was switched every $24 \mathrm{~h}$, and the intake volume was measured every $24 \mathrm{~h}$ for 3 days. During the experiment, each rat was kept in an individual plastic cage and fed solid food ad lib.

The bilateral sectioning of chorda tympani nerve (CT). Six rats were subjected to surgery for bilateral sectioning of the CT. Rats were anesthetized by i.p. injection of pentobarbital $(40 \mathrm{mg} / \mathrm{kg})$. Each animal was secured with a head holder in a prone position and an incision was made along the mandible tip.
Then both CT nerves were exposed and bilateral CT nerves were sectioned. After each operation, the wound was closed with autoclips and the animal was returned to its cage for recovery.

Cardiac and oral catheter surgeries. After rats reached a surgical level of anesthesia (pentobarbital, $40 \mathrm{mg} / \mathrm{kg}$, i.p.), cardiac catheterization $(0.5 \mathrm{~mm}$ inside diameter, $1.0 \mathrm{~mm}$ outer diameter) for blood collection was inserted from the right external jugular vein to the right atrium. The catheter exited and exposed about $3.0 \mathrm{~cm}$ from the parietal region through a hypodermic. Simultaneously, the catheter for the taste stimulation $(0.5 \mathrm{~mm}$ inside diameter, $1.0 \mathrm{~mm}$ outer diameter) was implanted into the oral cavity through the right cheek and exited and exposed about $3.0 \mathrm{~cm}$ from the parietal region through a hypodermic. After each operation, the animal was returned to its cage for recovery.

Samples and measurements. Taste stimulation and blood collection were performed under non-anesthesia and non-restraint using customary methods. Taste solutions $(1.0 \mathrm{~mL})$ were given for $45 \mathrm{~s}$ into the oral cavity via the oral catheter. After a 12-h fast, blood samples were obtained from the cardiac catheter at $-5,-1,1,3,5,7,9,11$ and 15 min after taste stimulation. Plasma glucose levels were determined by the glucose oxidase method (Glucose B-test, Wako Pure Pharmaceutical, Osaka, Japan). Plasma insulin concentrations were determined by ELISA kits (Morinaga, Yokohama, Japan).

Statistical analysis. All values are presented as means \pm SE. Statistical significance was examined by an ANOVA, with post hoc testing by means of Duncan's multiple range test. Comparisons between groups were made by Student's t-test. In all tests, $\mathrm{p}<0.05$ was accepted as significant.

\section{RESULTS}

Chorda tympani (CT) nerve responses and water intake for five fundamental taste solutions

The tongue was rinsed with distilled water. Gustatory $\mathrm{CT}$ nerve responses for various taste stimulations are shown in Fig. 1. 1.0 M sucrose, $0.1 \mathrm{M}$ acetic acid, $0.5 \mathrm{M} \mathrm{NaCl}, 0.01 \mathrm{M} \mathrm{QHCl}$ and $0.2 \mathrm{M}$ MSG elicited robust CT responses (12).

In Fig. 2, rats distinguished each taste solution from distilled water. Rats preferred sucrose solutions $(27.8 \pm 5.5 \mathrm{~mL} /$ day, $\mathrm{n}=4)$ but avoided other solutions (acetic acid: $1.1 \pm 0.7 \mathrm{~mL} /$ day, $\mathrm{n}=4 ; \mathrm{NaCl}$ : 

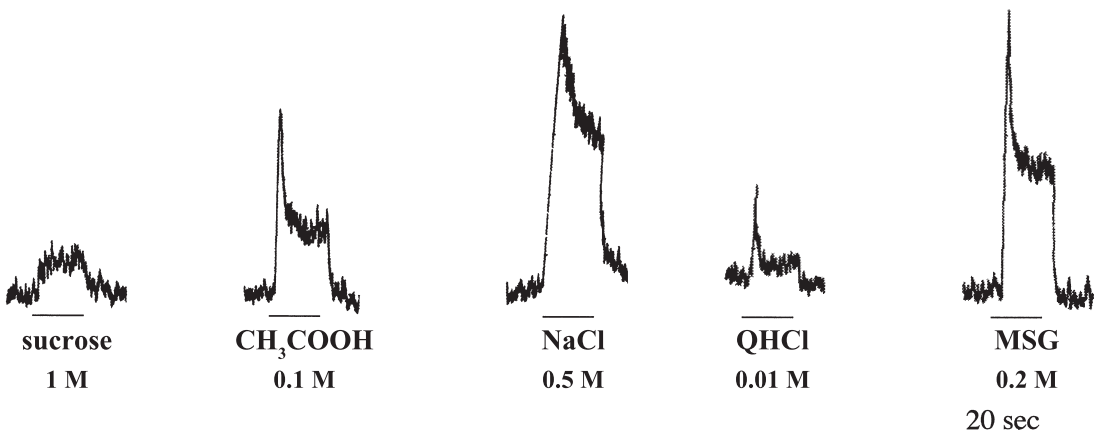

Fig. 1 Typical examples of integrated chorda tympani nerve responses to sucrose, acetic acid $\left(\mathrm{CH}_{3} \mathrm{COOH}\right)$, sodium chloride $(\mathrm{NaCl})$, quinine hydrochloride $(\mathrm{QHCl})$ and monosodium glutamate $(\mathrm{MSG})$.

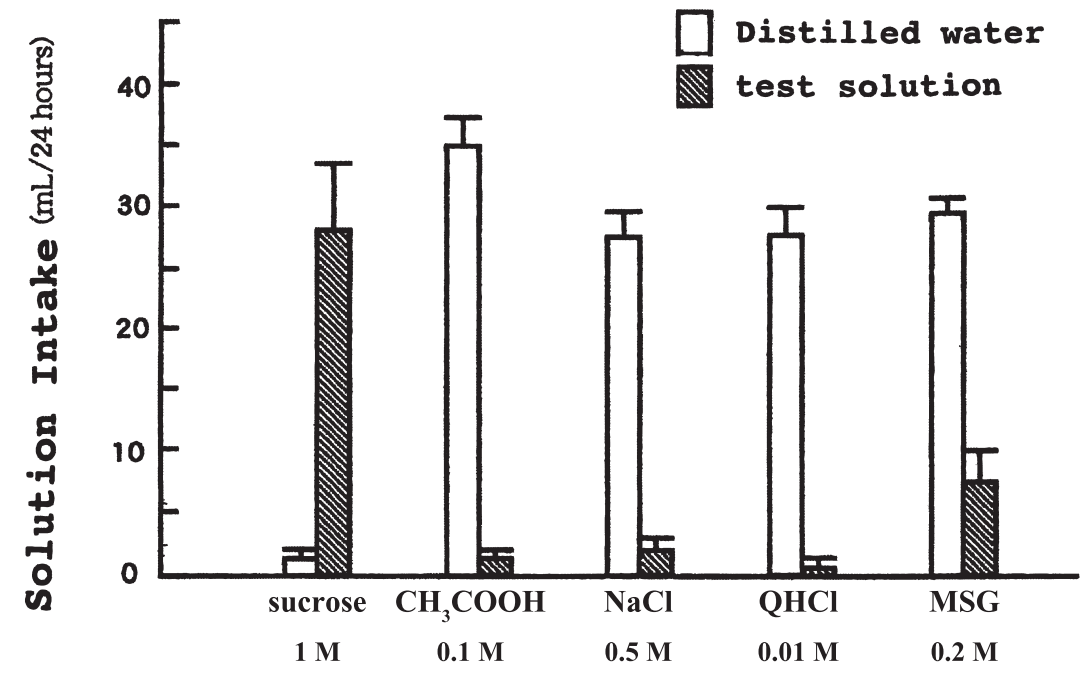

Fig. 2 Oral intake of taste solutions and distilled water during $24 \mathrm{~h}$ preference tests $(n=4)$. The open columns are the distilled water intake ratios, and the hatched columns are the taste stimulus solution intake ratios (mean $\pm S D$ ).

$2.2 \pm 0.8 \mathrm{~mL} /$ day, $\mathrm{n}=4$; QHCl: $0.7 \pm 0.7 \mathrm{~mL} /$ day, $\mathrm{n}=4$; MSG: $7.5 \pm 2.5 \mathrm{~mL} /$ day, $\mathrm{n}=4$ ). The water intake of a rat was $25.1 \pm 1.7 \mathrm{~mL} /$ day.

Five fundamental taste solutions and CPIR

In Fig. 3A, 3 min after the sucrose stimulation, there was a 3 to 4 times increase in plasma insulin concentration compared to levels prior to stimulation (before stimulation $3.0 \pm 0.7 \mathrm{ng} / \mathrm{mL}$ and after $3 \mathrm{~min}$ $12.4 \pm 4.5 \mathrm{ng} / \mathrm{mL}, \mathrm{n}=5$ ). The rise of the plasma insulin concentration was transient, and declined within $7 \mathrm{~min}$. In Fig. 3B, the change of the plasma glucose level after sucrose stimulation is plotted. The transient increase in insulin secretion was observed before the rise of the glucose level (before stimulation $88.5 \pm 8.5 \mathrm{mg} / \mathrm{dL}, 3 \mathrm{~min}$ after stimulation $99.3 \pm 8.5 \mathrm{mg} / \mathrm{dL}, \mathrm{n}=6,5 \mathrm{~min}$ after stimulation $112.2 \pm 6.5 \mathrm{mg} / \mathrm{dL}, \mathrm{n}=6,11 \mathrm{~min}$ after stimulation
$142.8+12.5 \mathrm{mg} / \mathrm{dL}, \mathrm{n}=6$ ). Thus CPIR was induced by the sucrose stimulation of the tongue. Table 1 presents the results of plasma insulin concentrations and plasma glucose concentrations for acetic acid, $\mathrm{NaCl}, \mathrm{QHCl}$ and MSG. No significant changes were observed.

\section{Sweetness and CPIR}

In presenting the 5 fundamental tastes, only sucrose elicited CPIR. However, sucrose has two characteristics: sweet and nutritive. Next, we tested whether 'sweet' or 'nutritive' could elicit CPIR. Testing with the non-nutritive sweetener saccharine did elicit CPIR (Fig. 4A and B). However, the non-sweetener nutritive starch did not elicit CPIR (Fig. 5A and B).

\section{The effect of bilateral sectioning CT nerve}

Finally, we studied whether CPIR was related to 
Table 1 Plasma insulin and glucose levels in rats

\begin{tabular}{|c|c|c|c|c|c|c|c|}
\hline & & before & 3 minutes & 5 minutes & 7 minutes & 11 minutes & $\mathrm{n}$ \\
\hline \multirow{2}{*}{$\begin{array}{l}\text { Acetic acid } \\
\text { sour }\end{array}$} & Insulin (ng/mL) & $2.5 \pm 0.2$ & $2.4 \pm 0.5$ & $2.3 \pm 0.2$ & $2.5 \pm 0.5$ & $2.5 \pm 0.5$ & 6 \\
\hline & Glucose $(\mathrm{mg} / \mathrm{dL})$ & $98.5 \pm 6.0$ & $93.5 \pm 0.2$ & $92.5 \pm 7.5$ & $92.5 \pm 7.0$ & $92.5 \pm 7.0$ & 5 \\
\hline \multirow{2}{*}{$\begin{array}{l}\mathrm{NaCl} \\
\text { salty }\end{array}$} & Insulin & $3.9 \pm 1.5$ & $3.4 \pm 1.1$ & $3.4 \pm 1.1$ & $3.4 \pm 1.5$ & $3.4 \pm 1.5$ & 5 \\
\hline & Glucose & $111.3 \pm 4.5$ & $110.5 \pm 4.0$ & $111.3 \pm 4.5$ & $110.5 \pm 4.0$ & $110.5 \pm 4.0$ & 5 \\
\hline \multirow{2}{*}{$\begin{array}{l}\text { QHCl } \\
\text { bitter }\end{array}$} & Insulin & $3.5 \pm 1.2$ & $2.9 \pm 1.0$ & $3.5 \pm 1.0$ & $3.5 \pm 1.0$ & $3.5 \pm 1.0$ & 5 \\
\hline & Glucose & $98.6 \pm 4.5$ & $98.0 \pm 4.5$ & $101.0 \pm 2.0$ & $101.0 \pm 2.0$ & $105.0 \pm 3.0$ & 5 \\
\hline \multirow{2}{*}{$\begin{array}{c}\text { MSG } \\
\text { umami }\end{array}$} & Insulin & $2.5 \pm 0.8$ & $2.5 \pm 0.8$ & $2.5 \pm 1.0$ & $2.5 \pm 1.0$ & $2.5 \pm 1.5$ & 5 \\
\hline & Glucose & $103.5 \pm 4.5$ & $103.5 \pm 4.5$ & $105.5 \pm 5.0$ & $105.5 \pm 5.0$ & $108.5 \pm 7.0$ & 5 \\
\hline
\end{tabular}

The values are indicated at $1 \mathrm{~min}$ before and 3, 5, 7,11 min after taste stimulation. n: sample numbers. Data are means $\pm \mathrm{SE}$.

A

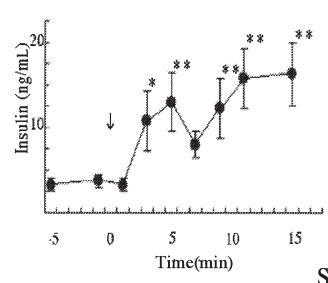

sucrose

Fig. 3 Effect of administration of sucrose on plasma insulin levels $(n=5)(A)$ and plasma glucose levels $(n=6)(B)$ $($ mean $\pm S D)$. Arrows indicate the beginning of the taste stimulation. Significant difference between conditions: ${ }^{*} \mathrm{P}<0.01$ and ${ }^{*} \mathrm{P}<0.05$.

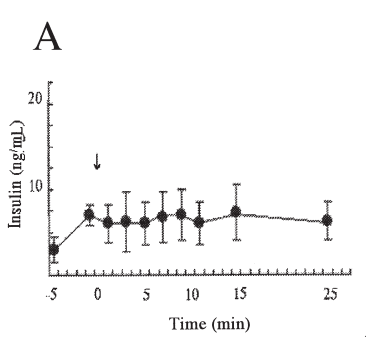

B

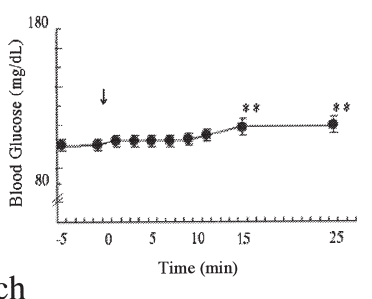

Fig. 5 Effect of administration of starch on plasma insulin levels $(n=5)(A)$ and plasma glucose levels $(n=5)(B)$ (mean $\pm \mathrm{SD}$ ). Arrows indicate the beginning of the taste stimulation. Significant difference between conditions: ${ }^{* *} \mathrm{P}<0.01$.

taste receptor cell activity. Experiments were carried out in rats with bilaterally cut $\mathrm{CT}$ nerves, one of the gustatory nerves. After sectioning, CPIR was not observed for sweet stimulation. The results are shown in Fig. 6A and B.

\section{DISCUSSION}

Five fundamental tastes, sweet, sour, salty, bitter and umami, were examined in order to clarify the rela-
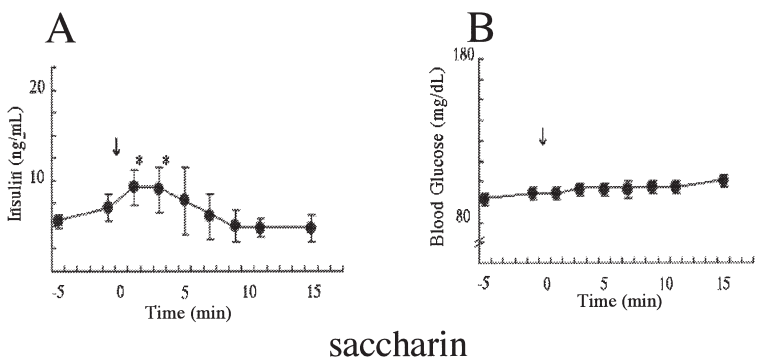

Fig. 4 Effect of administration of saccharine on plasma insulin levels $(n=5)(A)$ and plasma glucose levels $(n=5)(B)$ $($ mean $\pm S D)$. Arrows indicate the beginning of the taste stimulation. Significant difference between conditions: ${ }^{*} \mathrm{P}<0.05$.
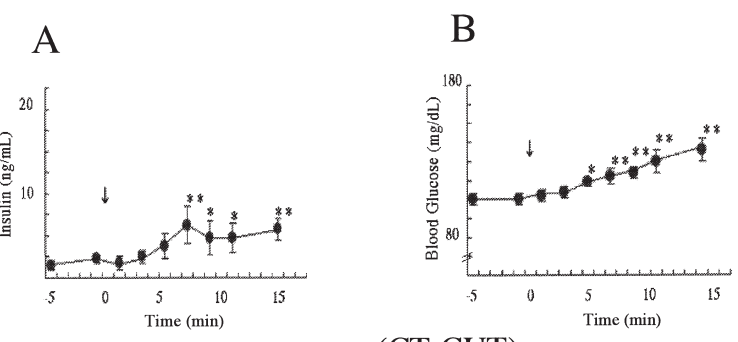

sucrose (CT:CUT)

Fig. 6 Effect of administration of sucrose on plasma insulin levels $(n=6)(A)$ and plasma glucose levels $(n=6)(B)$ with bilaterality sectioned the chorda tympani (CT) nerves (mean $\pm \mathrm{SD})$. An arrow indicates the beginning of the taste stimulation. Significant difference between conditions: ${ }^{* *} \mathrm{P}<0.01$ and ${ }^{*} \mathrm{P}<0.05$.

tionship between cephalic phase insulin release (CPIR) and taste quality since there are no previous reports examining the relationships between CPIR and these stimuli. In our experiments, the tongue was rinsed with distilled water and the taste cells were adapted to distilled water. Sucrose, acetic acid, $\mathrm{NaCl}, \mathrm{QHCl}, \mathrm{MSG}$ and saccharin elicited robust CT responses (12). The characteristic of CPIR is that plasma insulin secretion (plasma insulin release) oc- 
curs within 2 min after oral sensory stimulation, that is, the transient increase in insulin secretion was observed before the rise of the plasma glucose level. From our results, it is clear that CPIR was elicited only by sucrose stimulation, a sweet stimulus $(2,3$, 16). Since sucrose has two characteristics, sweet and nutritive, it is important to clarify which characteristic is related to CPIR. We tested both saccharin and starch: the artificial sweetener saccharin is sweet but not nutritive and starch is nutritive but not sweet. The non-nutritive sweetener saccharine did elicit CPIR whereas the non-sweetener nutritive starch did not. It has been reported that the rats show a strong preference for starch which is a source of glucose, but starch did not elicit CT responses $(8,10,11)$. From the results, it became clear that CPIR peculiarly appeared for sucrose, and it was proven that it is important that CPIR is elicited by sweet, not by nutritive stimuli. Next we studied whether CPIR was related to taste receptor cell activity. We carried out the experiment in rats with bilaterally cut CT nerves, one of the gustatory nerves. After sectioning, CPIR was not observed for sucrose stimulation. From these results, we conclude that sweetness information conducted by this taste nerve provides essential information for eliciting CPIR.

\section{REFERENCES}

1 Bellisle F, Louis-Sylvestre J, Demozay F, Blazy D and LeMagnen J (1983) Reflex insulin response associated to food intake in human subjects. Physiol Behav 31, 515-521.

2 Berridge K, Grill HJ and Norgren R (1981) Relation of consummatory responses and preabsorptive insulin release to palatability and learned taste aversions. J Comp Physiol Psychol 95, 363-382.

3 Berthoud HR, Trimble ER, Siegel EG, Bereiter DA and Jeanrenaud B (1980) Cephalic-phase insulin secretion in normal and pancreatic islet-transplanted rats. Am J Physiol 238, E336-E340.
4 Brand JG, Cagan RH and Naim M (1982) Chemical senses in the release of gastric and pancreatic secretions. Annu Rev Nutr 2, 249-276.

5 Hawkins RL, Inoue M, Mori M and Torii K (1994) Lysine deficient diet and lysine replacement affect food directed operant behavior. Physiol Behav 56, 1061-1068.

6 Hommel H,Fischer U, Retzlaff K and Knofler H (1972) The mechanism of insulin secretion after oral glucose administration. II. Reflex insulin secretion in conscious dogs bearing fistulas of the digestive tract by sham-feeding of glucose or tap water. Diabetologia 8, 111-116.

7 LeBlanc J, Soucy J and Nadeau A (1996) Early insulin and glucagon responses to different food items. Horm Metab Res 28, 276-279.

8 Nissenbaum JW and Sclafani A (1987) Qualitative differences in polysaccharide and sugar tastes in the rat: a two-carbohydrate taste model. Neurosci Biobehav Rev 11, 187-196.

9 Ohara I, Otsuka SI and Yugari Y (1979) The influence of carrier of gustatory stimulation on the cephalic phase of canine pancreatic secretion. $J$ Nutr 109, 2098-2105.

10 Sclafani A and Mann S (1987) Carbohydrate taste preferences in rats: glucose, sucrose, maltose, fructose and polycose compared. Physiol Behav 40, 563-568.

11 Sclafani A and Nissenbaum JW (1987) Taste preference thresholds for polycose, maltose, and sucrose in rats. Neurosci Biobehav Rev 11, 181-185.

12 Shimizu Y and Tonosaki K (1999) Low environmental temperature modulates gustatory nerve activity and behavioral responses to $\mathrm{NaCl}$ in rats. Am J Physiol 277, R368-R373.

13 Steffens AB (1976) Influence of the oral cavity on insulin release in the rat. Am J Physiol 230, 1411-1415.

14 Teff K (2000) Nutritional implications of the cephalic-phase reflexes: endocrine responses. Appetite 34, 206-213.

15 Teff KL, Levin BE and Engelman K (1993) Oral sensory stimulation in men: effects on insulin, C-peptide, and catecholamines. Am J Physiol 265, R1223-R1230.

16 Teff KL, Mattes RD, Engelman K and Mattern J (1993) Cephalic phase insulin release in obese and normal-weight men: relation to postprandial insulin. Metabolism 42, 1600-1608.

17 Teff KL and Engelman K (1996) Palatability and dietary restraint: effect on cephalic phase insulin release in women. Physiol Behav 60, 567-573.

18 Teff KL, Devine J and Engelman K (2000) Sweet taste: effect on cephalic phase insulin release in men. Physiol Behav 57, 1089-1095. 
